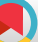

\title{
Protective Effect of Elaeagnus angustifolia L. Fruit Hydroalcoholic Extract on Cyclophosphamide-Induced Nephrotoxicity in Mice
}

\author{
Mehdi Goudarzi, ${ }^{1,2}$ Mahdi Esmaeilizadeh, ${ }^{3}$ Mojtaba Dolatshahi, ${ }^{1,4}$ Hadi Kalantar, ${ }^{2}$ Hossein \\ Frouzandeh, ${ }^{5}$ and Mojtaba Kalantar ${ }^{6,}$ \\ ${ }^{1}$ Student Research Committee, Ahvaz Jundishapur University of Medical Sciences, Ahvaz, Iran \\ ${ }^{2}$ Department of Toxicology, School of Pharmacy, Ahvaz Jundishapur University of Medical Sciences, Ahvaz, Iran \\ ${ }^{3}$ Student Research Committee, Esfarayen Faculty of Medical Sciences, Esfarayen, Iran \\ ${ }^{4}$ Department of Physiology, School of Medicine, Dezful University of Medical Sciences, Dezful, Iran \\ ${ }^{5}$ Gerash Cellular and Molecular Research Center, Gerash University of Medical Sciences, Gerash, Iran \\ ${ }^{6}$ Shoushtar Faculty of Medical Sciences, Shoushtar, Iran \\ "Corresponding author: Mojtaba Kalantar, Shoushtar Faculty of Medical Sciences, Shoushtar, Iran. Tel: +98-6133738378, E-mail: mojtaba.kalantar@yahoo.com
}

Received 2017 March 01; Revised 2017 July 01; Accepted 2017 October 16.

\begin{abstract}
Background: Cyclophosphamide (CP) is one of the most popular bifunctional alkylating agents, which is utilized in the treatment of numerous cancer diseases and has toxic side effects such as nephrotoxicity, hematotoxicity, mutagenicity, and immunotoxicity. In this study, Elaeagnus angustifolia fruit extract (EAFE), a natural plant extract, was examined for its antioxidant activity against CP-induced renal oxidative damage in mice.

Methods: In this experimental study, 30 male Swiss albino mice (25-30 g) were separated into five groups. Group 1 received normal saline for 5 days; group 2 was treated with CP $200 \mathrm{mg} / \mathrm{kg}$ single intraperitoneal (i.p) dose only on the 5th day; groups 3 to 5 received EAFE at doses of 100,200, and $400 \mathrm{mg} / \mathrm{kg}$, respectively, administered orally during 5 days, and CP on the 5 th day 1 hour after the last dose of extract administration. Then on the 6th day, the mice were sacrificed. Blood samples were collected to determine serum blood urea nitrogen (BUN) and creatinine (Cr) levels. Levels of malondialdehyde (MDA) and glutathione (GSH) in kidney tissue were also examined. Histological assessment was undertaken on kidney samples taken from all groups.

Results: The results obtained from our study showed a significant increase in the levels of MDA, Cr, and BUN and a decrease in GSH following CP injection. Pre-treatment with EAFE showed a decrease in the levels of MDA, Cr, and BUN and an increase in GSH in all doses; however, the most significant reduction was observed at doses of 200 and $400 \mathrm{mg} / \mathrm{kg}$. In addition, the nephroprotective effect of EAFE was confirmed by histological evaluation of the kidneys.

Conclusions: Our results indicate that EAFE has protective effects against CP-induced renal damage possibly by amelioration of biochemical indices and oxidative stress parameters.
\end{abstract}

Keywords: Cyclophosphamide, Nephrotoxicity, Mice, Elaeagnus angustifolia

\section{Background}

Cyclophosphamide (CP) has been used widely in malignant tumors chemotherapy expressing toxicity whenever metabolically activated (1). CP is the most effective medicine in remedies for both neoplastic diseases, where it acts as an immunosuppressant in organ transplantation, and non-neoplastic diseases such as rheumatoid arthritis, systemic lupus erythematous, and multiple sclerosis (2). It is well known that $\mathrm{CP}$ and its reactive metabolites via DNA producing cross-links are responsible for its adverse reactions (3). Applying this drug also causes the generation of ROS (reactive oxygen species) (4), which leads to oxidative injury to the urinary bladder and might cause renal dys- function (5). A number of studies have demonstrated that CP cure for non-Hodgkin's syndrome causes side effects in the kidney as well as in urinary bladder (6). Additionally, it is identified that $\mathrm{CP}$ and its metabolites may lead to kidney injure and severe inflammation in the bladder $(7,8)$. Recently, after showing the relationship between oxidative stress and human diseases, interest in nutritional supplements and components containing antioxidant elements has grown. These types of substances assist in preventing most of the oxidative reactions involving free radicals such as superoxide, hydroxyl, and proxy nitrate and thus may slow or inhibit the progression of diseases (9).

Elaeagnus angustifolia fruit commonly called Wild 
olive, Silverberry, Russian olive, or oleaster is a species of Elaeagnus native to Iran (commonly called Senjed), western and central Asia (10). Species of Elaeagnus angustifolia fruit has a variety of medicinal uses. Elaeagnus angustifolia, as an herbal drug, has been applied in Iranian traditional medicine as a sedative agent for pain relief in rheumatoid arthritis as well as for treatment of nausea, vomiting, jaundice, asthma, flatulence, and as an antipyretic, diuretic, and medication against kidney disorders (11-13).

Phytochemical studies of E. angustifolia L. fruit extract indicate the presence of flavonoid compounds, polysaccharides, sitosterols, cardiac glycosides, terpenoids, coumarins, phenol, carboxylic acids, amino acids, saponins, carotenoids, vitamins, and tannins (11, 14, 15). Some groups of flavonoids such as quercetin, luteolin, catechin, kaempferol, epicatechin, epigallocatechin, and gallocatechin have been isolated and known in the extract of E. angustifolia (15). Medicinal properties of Elaeagnus angustifolia are due to its valuable compounds and their antioxidant properties. Therefore, this plant can be used as a remedial source (16).

\section{Objectives}

In the current study, we examined the ameliorative activity of oral Elaeagnus angustifolia fruit extract (EAFE) against CP-induced oxidative stress in rat kidney tissues.

\section{Methods}

\subsection{Chemicals}

Bradford reagents, bovine serum albumin (BSA), 1,1,3,3Tetramethoxypropane (TEP), Thiobarbituric acid (TBA), Trichloroacetic acid (TCA), 5,5'-Dithiobis(2-nitrobenzoic acid) (DTNB), and Reduced glutathione (GSH) were purchased from Sigma-Aldrich company (St. Louis, MO), USA. $\mathrm{CP}$ was purchased from Roche chemical company (Germany).

\subsection{Extract Preparation}

The fruits and other plant materials were collected from the Iranian province of Ardabil during spring 2015. Samples were taxonomically identified by central herbarium of Ahvaz Jundishapur University of Medical Sciences, Iran, where the voucher specimens were preserved (number voucher: A-0137). Extraction was done according to the maceration method as follows: 100 grams of the fruits were shade-dried, ground, and soaked in $500 \mathrm{~mL}$ of $70 \%$ aqueous-ethanol for three days with periodic shaking. The solvent obtained from the previous step was refined through a filter paper (Whatman No. 2) and then evaporated in vacuum conditions in a rotary evaporator until dryness of extract. The ratio efficiency of extract was $14 \%$ $(w / w)$ for dried hydroalcoholic extract.

\subsection{Animals}

Male Swiss albino mice weighing 25 - 30 g were obtained from the animal house of Ahvaz Jundishapur University of Medical Science, Ahvaz, Iran. The mice were kept under controlled conditions of temperature (25 \pm $2^{\circ} \mathrm{C}$ ) with a 12 hours light: 12 hours dark cycle, in polycarbonate cages. All mice were given standard rat chow and drinking water ad libitum. The research was conducted according to the animal ethics committee guidelines for the use of experimental animals (ethics approval number: IR.AJUMS.REC.1395.640).

\subsection{Experimental Design}

The animals were equally divided into five groups; each group consisted of six mice. Group 1 received orally normal saline for 5 days; group 2 received CP (200 mg/kg, ip) only on the 5th day, groups 3 - 5 received EAFE orally at doses of 100,200 , and $400 \mathrm{mg} / \mathrm{kg}$, respectively, during 5 days and CP (200 mg/kg, ip) on the 5 th day 1 hour after the last gavage dose of the extract.

\subsection{Sample Collection}

On the 6th day, the animals were sacrificed using ketamine and xylazine over dose and blood samples were collected from the jugular vein. The serum was separated by centrifugation at $3000 \mathrm{rpm}$ for 10 minutes and stored at $-20^{\circ} \mathrm{C}$ until analysis. The kidneys were removed immediately and washed with saline. Then, the right kidney saved in 10\% buffered formalin for histopathological evaluation. The left kidney was homogenized (1/10 w/v) in icecold Tris-HCl buffer (0.1 M, pH 7.4). Protein content in homogenates was measured by the Bradford method (17) using crystalline BSA as standard (18).

\subsection{Glutathione (GSH) Assay}

The levels of GSH in the homogenate kidney tissue were measured according to the Ellman method based on the formation of a yellow colored complex with Ellman's Reagent (5,5'-dithiobis-(2-nitrobenzoic acid) or DTNB) (19). Homogenates tissues were quickly precipitated with 0.1 $\mathrm{mL}$ of $25 \%$ TCA and the precipitate was removed after centrifugation. Free endogenous-SH was assayed in a $3 \mathrm{~mL}$ volume glass by addition of $2 \mathrm{~mL}$ of $0.5 \mathrm{mM}$ DTNB prepared in $0.2 \mathrm{M}$ phosphate buffer $(\mathrm{pH}=8)$ to $0.1 \mathrm{~mL}$ of the supernatant and the yellow color developed was read at $412 \mathrm{~nm}$ using a spectrophotometer. The standard curve was constructed over the concentration range of $1-10 \mu \mathrm{M}$ of GSH. GSH content was expressed as $\mathrm{nmol} / \mathrm{mg}$ protein. 


\subsection{Lipid Peroxidation Assay}

The lipid peroxidation was shown by assessing the concentrations of MDA via TBA pink color reaction. According to the method explained by Buege and Aust, $0.5 \mathrm{~mL}$ of homogenate was combined with $2.5 \mathrm{~mL}$ of TCA $(10 \%$, $\mathrm{w} / \mathrm{v})$. The samples obtained were centrifuged at $3000 \mathrm{rpm}$ for 10 minutes and $2 \mathrm{~mL}$ of each sample supernatant was moved to examination pipe containing $1 \mathrm{~mL}$ of TBA solution $(0.67 \%, w / v)$. The combination was saved in boiling water for 10 minutes, developing a pink color solution. After this step, the mixture was cooled quickly and the absorbance was read at $532 \mathrm{~nm}$ by spectrophotometer. The level of MDA was calculated according to the absorbance coefficient of the TBA-MDA complex $\left(\varepsilon=1.56 \times 105 \mathrm{~cm}^{-1} \mathrm{M}^{-1}\right)$ (20).

\subsection{Histopathological Assessments}

On the last day, the kidneys were fixed in $10 \%$ formalin solution. Then, they were dehydrated in graded alcohol concentrations and embedded in paraffin. Sections of 4 - $6 \mu \mathrm{m}$ were prepared and stained with hematoxylin and eosin (H and E). Six microscopy slides per animal were examined for assessment of histological changes such as edema, necrosis, mononuclear/polymorph nuclear cell infiltration, hemorrhage, and narrowing of Bowman's capsule space. Slides were evaluated in a "blind" fashion.

\subsection{Statistical Analysis}

The results were expressed as mean \pm SD. The statistical analyses were performed using one-way ANOVA followed by Tukey's test by GraphPad Prism Version 5.01 (GraphPad Software Inc., San Diego, CA, USA). For all tests, differences with values of $\mathrm{P}<0.05$ were considered significant.

\section{Results}

Twenty-four hours after $\mathrm{CP}$ administration, the mice developed severe nephrotoxicity that was reflected by a significant enhancement $(\mathrm{P}<0.001)$ in the BUN levels (Figure 1) as compared to the control group. The pre-treated groups with EAFE showed reduced levels of BUN at all administered doses although the reduction was more significant $(\mathrm{P}<0.01)$ at dose of $200 \mathrm{mg} / \mathrm{kg}$.

A significant increase $(\mathrm{P}<0.001)$ was found in the levels of creatinine (Figure 2 ) as compared to the control group. The pre-treated groups with EAFE displayed a decrease in the level of creatinine at all doses but the decrease was more significant $(\mathrm{P}<0.01)$ at $400 \mathrm{mg} / \mathrm{kg}$ dose.

Figure 3 shows the effect of $\mathrm{CP}$ and EAFE pretreatment on the level of GSH in kidney tissues. The results obtained Figure 1. Effects of Pretreatment with Elaeagnus Angustifolia Fruit Extract (EAFE) on
the Serum Levels of BUN in Cyclophosphamide (CP) Induced Nephrotoxicity

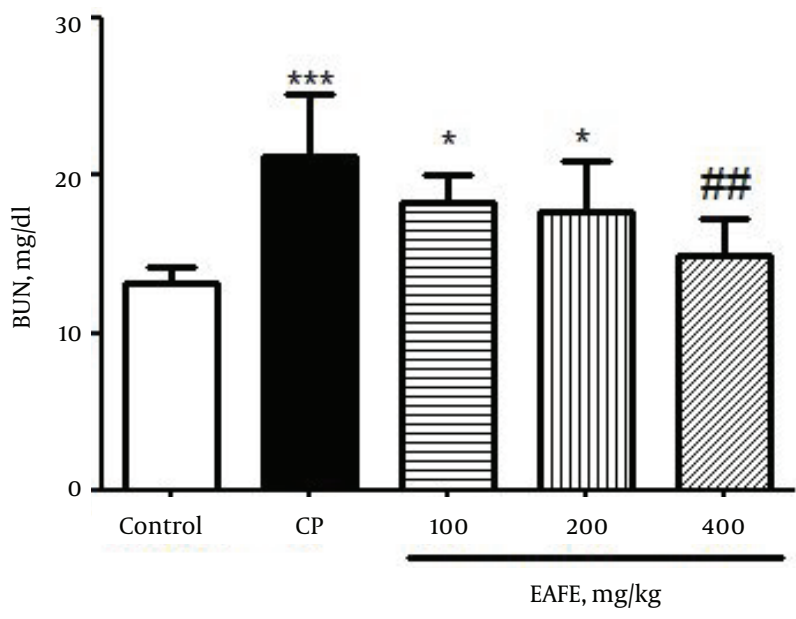

All values are expressed as Mean $\pm S D, n=6 .{ }^{*}$ A significant increase in comparison with the control group $\left({ }^{*} \mathrm{P}<0.05\right.$ and $\left.{ }^{* * *} \mathrm{P}<0.001\right) .{ }^{\#} \mathrm{~A}$ significant decrease in comparison with the CP group $\left({ }^{\# \#} \mathrm{P}<0.01\right)$

Figure 2. Effects of Pretreatment with Elaeagnus Angustifolia Fruit Extract (EAFE) on the Serum Creatinine (Cr) Levels in Cyclophosphamide (CP) Induced Nephrotoxicity

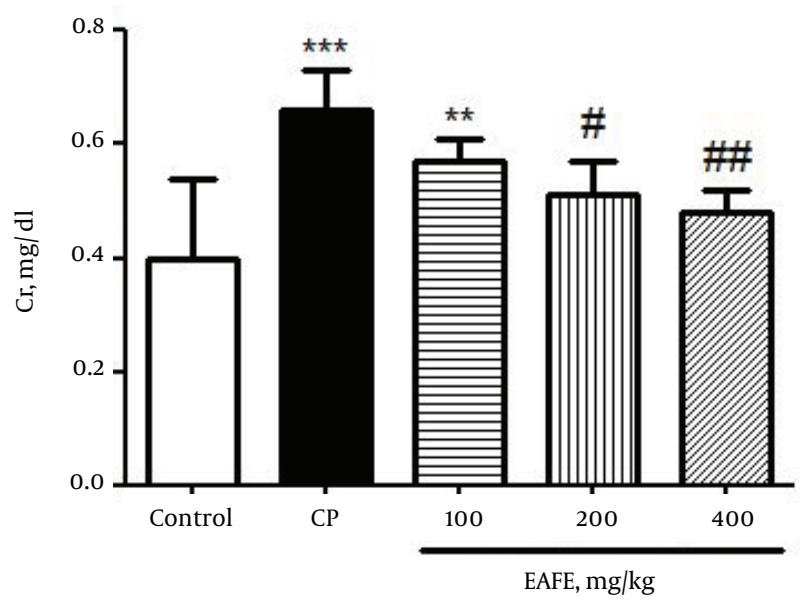

All values are expressed as Mean $\pm S D, n=6$. *A significant increase in comparison with the control group $\left({ }^{* *} \mathrm{P}<0.05\right.$ and $\left.{ }^{* * *} \mathrm{P}<0.001\right)$. ${ }^{*} \mathrm{~A}$ significant decrease in comparison with the CP group $\left({ }^{\#} \mathrm{P}<0.05\right.$ and $\left.{ }^{\# \#} \mathrm{P}<0.01\right)$.

from Figure 3 showed that the administration of CP led to a significant depletion in renal GSH $(\mathrm{P}<0.001)$ as compared to the control group. On the contrary, pretreatment with EAFE caused a diminished level of MDA when compared to the CP group $(\mathrm{P}<001)$.

In Figure 4, the results clearly revealed that $\mathrm{CP}$ intoxication resulted in a marked increase in the level of MDA in rats $(\mathrm{P}<0.001)$ as compared to the control group. In com- 
Figure 3. Effects of Pretreatment with Elaeagnus Angustifolia Fruit Extract (EAFE) on the GSH Levels in Cyclophosphamide (CP) Induced Nephrotoxicity

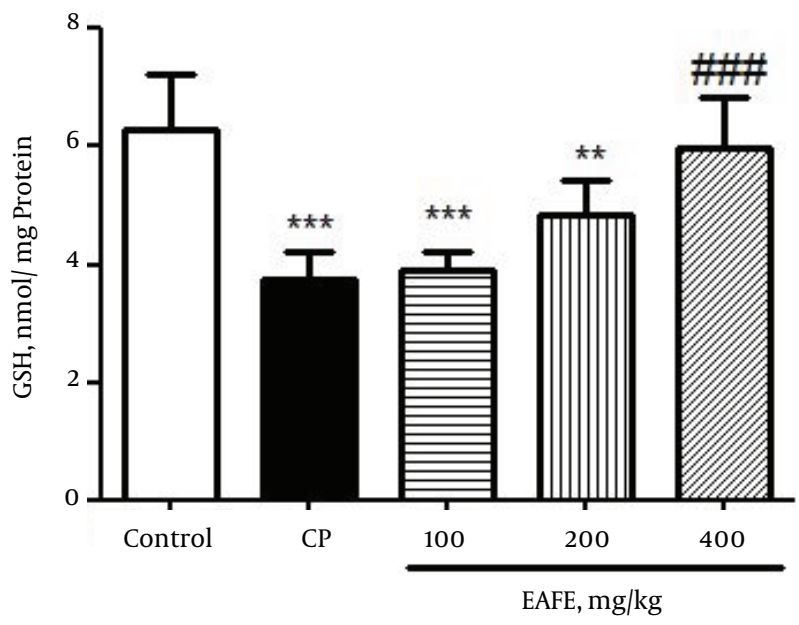

All values are expressed as Mean $\pm S D, n=6 .{ }^{*}$ A significant increase in comparison with the control group $\left({ }^{* *} \mathrm{P}<0.05\right.$ and $\left.{ }^{* * *} \mathrm{P}<0.001\right) .{ }^{\#} \mathrm{~A}$ significant decrease in comparison with the CP group $\left({ }^{\# \# \#} \mathrm{P}<0.001\right)$.

parison, pretreatment with EAFE caused a diminished level of $\operatorname{MDA}(\mathrm{P}<0.001)$.

Figure 4. Effects of Pretreatment with Elaeagnus Angustifolia Fruit Extract (EAFE) on the MDA Levels in Cyclophosphamide (CP) Induced Nephrotoxicity

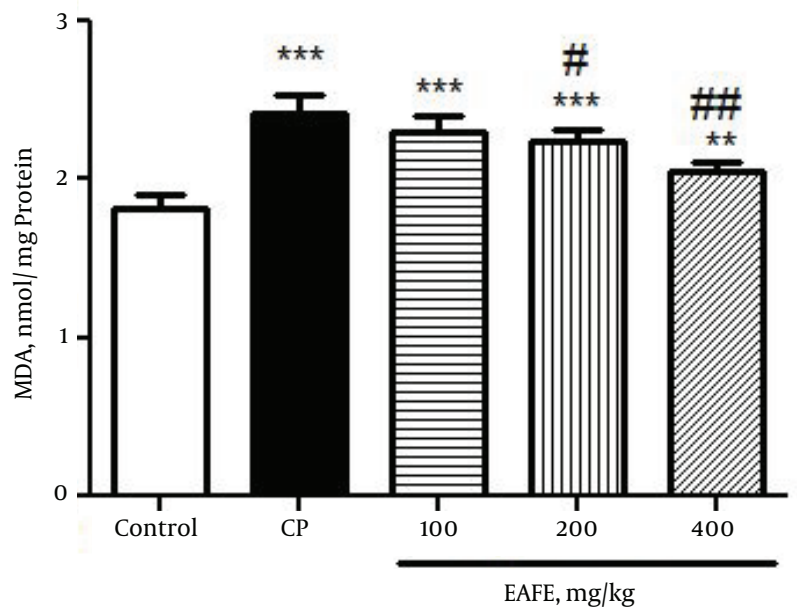

All values are expressed as Mean $\pm S D, n=6$. *a significant increase in comparison with the control group $\left({ }^{* *} \mathrm{P}<0.05\right.$ and $\left.{ }^{* * *} \mathrm{P}<0.001\right)$. " a significant decrease in comparison with the CP group $\left({ }^{\#} \mathrm{P}<0.05\right.$ and $\left.{ }^{\# \#} \mathrm{P}<0.01\right)$.

The histopathological study of kidney in the negative control group showed a normal architecture. In this group, the distal convoluted tubules and structure of epithelial cells in proximal convoluted tubules were normal, the boundaries of the visceral layer and parietal layer of renal capsule were obvious, the structure of glomerular was very clear, and capsular space was small (Figure 5A). In the CP-intoxicated group, the glomerular was atrophied and disintegrated, capsular spaces became expanded obviously, the parietal layer and visceral layer of kidney capsule were damaged and some of them were vanished, the epithelial cells in proximal convoluted tubules and distal convoluted tubule were inflamed, several epithelial cells had vacuolization, the structure of epithelial cells was not clear, and there were some cell pieces in the tubules (Figure 5B).

Pretreatment with EAFE at doses of 200 and $400 \mathrm{mg} / \mathrm{kg}$ showed considerable improvements in proximal and distal convoluted tubules (Figure 5D, E). The atrophy degree of glomeruli decreased and the capsular spaces were smaller in comparison with the $\mathrm{CP}$ treated group. The boundaries of the parietal layer and visceral layer of kidney capsule were obvious, the epithelial cells in distal and proximal convoluted tubules were slightly swollen, and cell fragments were visible in some tubules.

\section{Discussion}

In the kidneys, cyclophosphamide (CP) generation of inflammatory mediators, nitric oxide, growth factors, and cytokines, which play an important role in cellular stress response, are considerable (21). An oxidative stress was formulated from a disturbance between the generation of reactive oxygen species (ROS) and their elimination through antioxidant systems. The GSH either can be regarded as a non-enzymatic anti-oxidant through interplaying between ROS and SH group or may be implicated in the enzymatic detoxification response for ROS as a cofactor (22). The MDA, an indicator of oxidative damage, increases in body after injection of $\mathrm{CP}$, resulting in the ultimate damage to membrane lipids with the creation and diffusion of free radicals and raised uptake of oxygen, leading to the transformation of the double bonds in unsaturated lipid.

Previous studies showed that topical application of $E$. angustifolia L. fruit extract to a wounded area could increase the content of hydroxyproline, an important factor in making collagen, in the tissue $(14,23)$. In addition, another study showed that E. angustifolia $\mathrm{L}$. fruit extract has a significant effect on accelerating the wound healing process and reducing the inflammation and pain in rats (14). In Iranian traditional medicine, dried powdered leaves of oleaster (Persian; Senjed) have been used as a remedy to control bleeding and accelerate the wound healing process $(14,24)$. The result of another study suggests that after administration of the methanolic fruit extract 
Figure 5. Histopathological Observations (Kidney Sections Stained with Hematoxylin and Eosin, Magnification x 100) Showing the Effects of EAFE on Cyclophosphamide -Induced Nephrotoxicity Changes in Mice Kidney
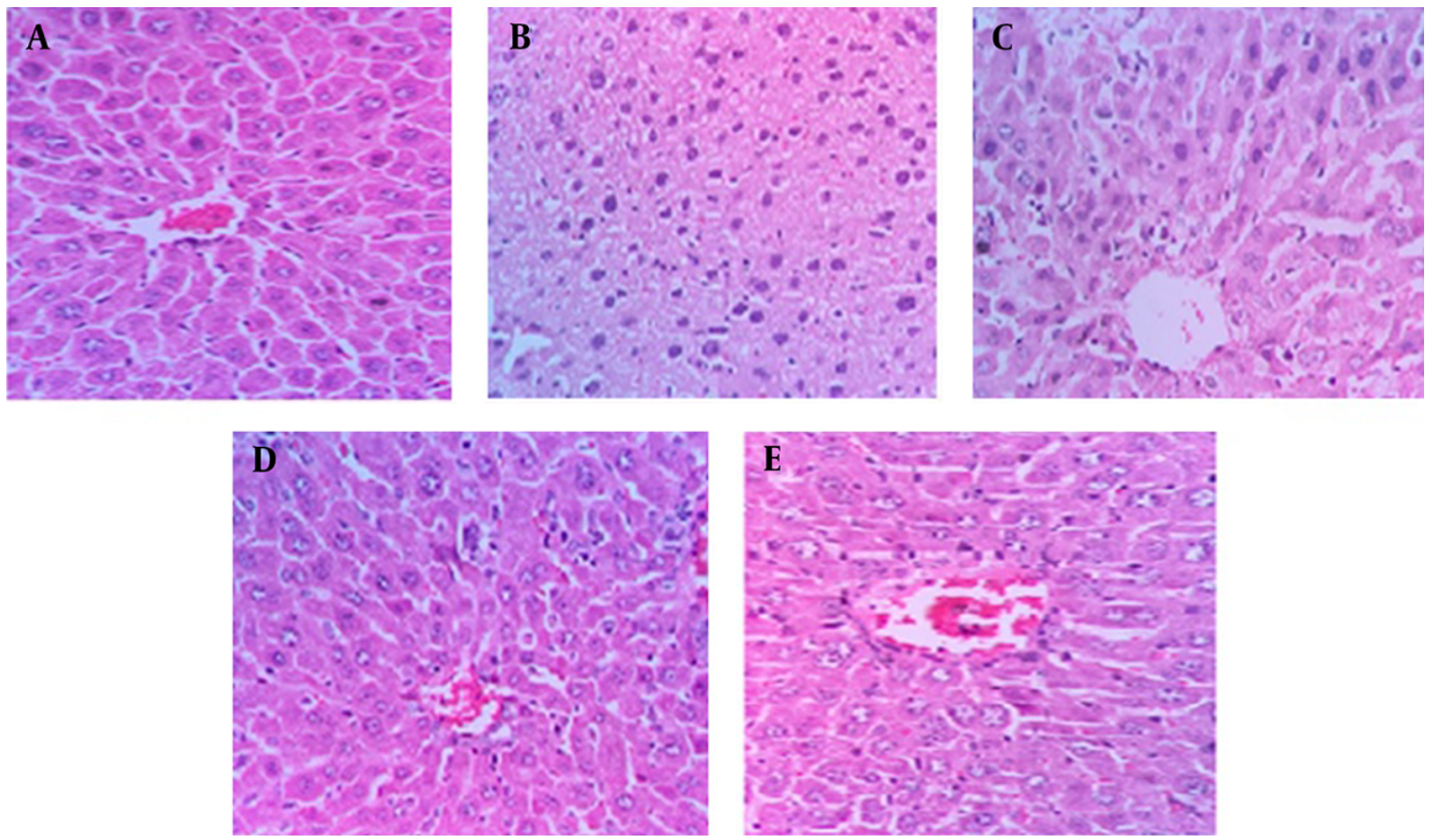

A, Normal; B, CP treated group; C, D and E, CP groups pre-treated with 100, 200, and $400 \mathrm{mg} / \mathrm{kg}$ EAFE, respectively.

of E. angustifolia in rats with ethanol-induced gastric ulcer, a strong gastroprotective activity was observed as evidenced by histopathological examination and ulcer index determination (25). Further studies assessed the pharmacological mechanism of action of E. angustifolia extract in vascular and respiratory smooth muscle cells (26). A previous study showed the effectiveness of aqueous extract of $E$. angustifolia leaves, and its cardioprotective activity on induced ischemia/reperfusion was demonstrated in isolated rat heart. The results indicated that the leaves extract of E. angustifolia has protective effects on myocardial ischemia-reperfusion injury that can be attributed to the increase in antioxidant activity by the extract in the myocardial tissues (27). Several studies have shown that the use of an aqueous extract of E. angustifolia fruit is effective in reducing the pain and inflammation in animal models as well as in patients with atherosclerosis. The extract has the ability to inhibit the activity of cyclooxygenase 1 and 2 enzymes and it seems to be a right candidate to become a good anti-inflammatory drug, as well (28). The report of a previous study indicated that the effectiveness of extract of E. angustifolia L. in reducing chronic pain and inflammation is comparable to that of chemi- cal drugs such as non-steroidal anti-inflammatory drugs (NSAIDs), indomethacin, and dexamethasone (26). The results obtained from another study suggest that the combination of ginger and E. angustifolia extract is safe and can be effective in reducing pain in patients suffering from osteoarthritis (29). In the study by Morris, the effect of water extract of E. angustifolia L. was examined in rats with temporarily impaired memory and learning by scopolamine injection. The results showed that spatial learning and memory of the scopolamine-induced rats improved dosedependently with an increase in the intake of E. angustifolia water extract $(30,31)$. In an experiment, the antioxidant and anti-tumor activity of different fractions of acetic ether extract of E. angustifolia L. were studied. With the increase of concentration and polarity level of each sample, the antioxidant and radical scavenging activities increased.

In the present study, hydroalcoholic crude extract of EAFE significantly inhibited the acute kidney toxicity induced by high doses of $\mathrm{CP}$ in mice, as shown by a reduction in BUN, creatinine, and MDA levels and an increase in GSH.

Furthermore, the protective effects of EAFE were confirmed by histopathological studies of kidney showing considerable improvements in proximal and distal con- 
voluted tubules and atrophy of glomerular in pretreated groups. Our results demonstrated that the protective effects of EAFE were dose-dependent, and the best results were obtained in doses of 200 and $400 \mathrm{mg} / \mathrm{kg}$. We believe that this protective effect is probably mediated by antioxidant and glutathione preservation effects of EAFE.

In conclusion, the results of the study indicated that hydroalcoholic extract of EAFE showed protective effects against CP-induced nephrotoxicity in mice.

We generated oxidative damage to the rat kidney utilizing CP. Research has been described that CP is a beneficial agent for the study of oxidative stress since its toxicity is mediated by free radicals. The current research showed that CP-induced oxidative stress was protected by EAFE administration. Nevertheless, main restriction in the current study was a phytochemical analysis to find the active ingredients of the plant extract.

\section{Acknowledgments}

This work was supported by a grant numbered $94 s 156$ provided by the deputy of research of Ahvaz Jundishapur University of Medical Sciences, Ahvaz, Iran.

\section{Footnotes}

Authors' Contribution: Mehdi Goudarzi and Mojtaba Kalantar designed the study and interpreted the data. Hossein Frouzandeh, Mahdi Esmaeilizadeh, and Mojtaba Dolatshahi collected the data, performed experimental analysis, and interpreted the data. Hadi Kalantar and Mojtaba Kalantar drafted the manuscript. All the authors read and approved the final version of the manuscript.

Conflict of Interest: All authors declare no conflict of interest related to the present work.

\section{References}

1. Baumann F, Preiss R. Cyclophosphamide and related anticancer drugs. J Chromatogr B Biomed Sci Appl. 2001;764(1-2):173-92. doi: 10.1016/S0378-4347(01)00279-1. [PubMed: 11817027].

2. Uber WE, Self SE, Van Bakel AB, Pereira NL. Acute antibodymediated rejection following heart transplantation. Am J Transplant. 2007;7(9):2064-74. doi: 10.1111/j.1600-6143.2007.01900.x. [PubMed: 17614978].

3. Hales BF. Comparison of the mutagenicity and teratogenicity of cyclophosphamide and its active metabolites, 4hydroxycyclophosphamide, phosphoramide mustard, and acrolein. Cancer Res. 1982;42(8):3016-21. [PubMed: 7046914].

4. Martinasso G, Maggiora M, Trombetta A, Canuto RA, Muzio G. Effects of di(2-ethylhexyl) phthalate, a widely used peroxisome proliferator and plasticizer, on cell growth in the human keratinocyte cell line NCTC 2544. J Toxicol Environ Health A. 2006;69(5):353-65. doi: 10.1080/15287390500227522. [PubMed: 16455614].
5. Patel JM. Stimulation of cyclophosphamide-induced pulmonary microsomal lipid peroxidation by oxygen. Toxicology. 1987;45(1):79-91. doi:10.1016/0300-483X(87)90116-8. [PubMed: 3603576].

6. Travis LB, Curtis RE, Glimelius B, Holowaty EJ, Van Leeuwen FE, Lynch CF, et al. Bladder and kidney cancer following cyclophosphamide therapy for non-Hodgkin's lymphoma. J Natl Cancer Inst. 1995;87(7):524-30. doi:10.1093/jnci/87.7.524. [PubMed: 7707439].

7. Abraham $\mathrm{P}$, Isaac $\mathrm{B}$. The effects of oral glutamine on cyclophosphamide-induced nephrotoxicity in rats. Hum Exp Toxicol. 2011;30(7):616-23. doi: 10.1177/0960327110376552. [PubMed: 20621952].

8. Lawson M, Vasilaras A, De Vries A, Mactaggart P, Nicol D. Urological implications of cyclophosphamide and ifosfamide. Scand J Urol Nephrol. 2008;42(4):309-17. doi: 10.1080/00365590701570953. [PubMed: 18781541].

9. Saboonchian F, Jamei R, Hosseini Sarghein S. Phenolic and flavonoid content of Elaeagnus angustifolia L. (leaf and flower). Avicenna J Phytomed. 2014;4(4):231-8. [PubMed: 25068137].

10. McMillan X. A concise dictionary of plants cultivated in the United States and Canada. New York: Hortorium Cornell University; 1976. pp. 1161-2.

11. Ayaz FA, Bertoft E. Sugar and phenolic acid composition of stored commercial oleaster fruits. J Food Compost Anal. 2001;14(5):505-11. doi: 10.1006/jfca.2001.1004.

12. Gurbuz I, Ustun O, Yesilada E, Sezik E, Kutsal O. Anti-ulcerogenic activity of some plants used as folk remedy in Turkey. J Ethnopharmacol. 2003;88(1):93-7. doi: 10.1016/S0378-8741(03)00174-0. [PubMed: 12902057].

13. Hosseinzadeh H, Ramezani M, Namjo N. Muscle relaxant activity of Elaeagnus angustifolia L. fruit seeds in mice. $J$ Ethnopharmacol. 2003;84(2-3):275-8. doi: 10.1016/S0378-8741(02)00331-8. [PubMed: 12648826].

14. Mehrabani Natanzi M, Pasalar P, Kamalinejad M, Dehpour AR, Tavangar SM, Sharifi R, et al. Effect of aqueous extract of Elaeagnus angustifolia fruit on experimental cutaneous wound healing in rats. Acta Med Iran. 2012;50(9):589-96. [PubMed: 23165807].

15. Okmen G, Turkcan O. A study on antimicrobial, antioxidant and antimutagenic activities of Elaeagnus angustifolia L. leaves. Afr J Tradit Complement Altern Med. 2014;11(1):116-20. [PubMed: 24653563].

16. Wang Y, Guo T, Li JY, Zhou SZ, Zhao P, Fan MT. Four flavonoid glycosides from the pulps of Elaeagnus angustifolia and their antioxidant activities. Adv Mat Res. 2013;756-9:16-20. doi: 10.4028/www.scientific.net/AMR.756-759.16.

17. Bradford MM. A rapid and sensitive method for the quantitation of microgram quantities of protein utilizing the principle of protein-dye binding. Anal Biochem. 1976;72:248-54. doi: 10.1016/00032697(76)90527-3. [PubMed: 942051].

18. Kalantar M, Shirali S, Hasanvand A, Valizadeh M, Tavakoli R, Asadi M. Ameliorative effects of hydroalcoholic extract of lavandula officinalis L. on methotrexate-induced oxidative stress in rats. Pharm Sci. 2017;23(1):18-26.

19. Ellman GL. Tissue sulfhydryl groups. Arch Biochem Biophys. 1959;82(1):70-7. doi: 10.1016/0003-9861(59)90090-6. [PubMed: 13650640].

20. Buege JA, Aust SD. Microsomal lipid peroxidation. Methods Enzymol. 1978;52:302-10. doi: 10.1016/S0076-6879(78)52032-6. [PubMed: 672633].

21. Kalantar M, Goudarzi M, Khodayar MJ, Babaei J, Foruozandeh H, Bakhtiari N, et al. Protective effects of the hydroalcoholic extract of Capparis spinosa L. against cyclophosphamide-induced nephrotoxicity in mice.JundishapurJ Nat Pharm Prod. 2016;11(4) doi: 10.17795/jjnpp37240.

22. Rehman MU, Tahir M, Ali F, Qamar W, Lateef A, Khan R, et al. Cyclophosphamide-induced nephrotoxicity, genotoxicity, and damage in kidney genomic DNA of Swiss albino mice: the protective effect of Ellagic acid. Mol Cell Biochem. 2012;365(1-2):119-27. doi: 10.1007/s11010-012-1250-x. [PubMed: 22286819]. 
23. Mehrabani NM, Gerayesh Nejad S, Kamalinejad M, Dehpour AR, Tavangar SM, Sharify R, et al. Histological changes and wound healing response following use of aqueous extract of Elaeag nus angustifolia in albino rats. Clin Biochem. 2011;44(13):39. doi: 10.1016/j.clinbiochem.2011.08.1050.

24. Koca U, Suntar I, Akkol EK, Yilmazer D, Alper M. Wound repair potential of Olea europaea L. leaf extracts revealed by in vivo experimental models and comparative evaluation of the extracts' antioxidant activity. J Med Food. 2011;14(1-2):140-6. doi: 10.1089/jmf.2010.0039. [PubMed: 21128831].

25. Mohammed FI. Investigation of the direct effects of the alcoholic extract of Elaeagnus angustifolia L. (elaeagnaceae) on dispersed intestinal smooth muscle cells of Guinea Pig. Sci Pharm. 2006;74(1):21-30. doi: 10.3797/scipharm.2006.74.21.

26. Hamidpour R, Hamidpour S, Hamidpour M, Shahlari M, Sohraby $\mathrm{M}$, Shahlari N, et al. Russian olive (Elaeagnus angustifolia L.): From a variety of traditional medicinal applications to its novel roles as active antioxidant, anti-inflammatory, anti-mutagenic and analgesic agent. J Tradit Complement Med. 2017;7(1):24-9. doi: 10.1016/j.jtcme.2015.09.004. [PubMed: 28053884].
27. Wang B, Qu H, Ma J, Sun X, Wang D, Zheng Q, et al. Protective effects of Elaeagnus angustifolia leaf extract against myocardial ischemia/reperfusion injury in isolated rat heart.JChem. 2014;2014:1-6. doi: 10.1155/2014/693573.

28. Farahbakhsh S, Arbabian S, Emami F, Rastegar Moghadam B, Ghoshooni H, Noroozzadeh A. Inhibition of Cyclooxygenase type 1 and 2 enzyme by aqueous extract of Elaeagnus angustifolia in mice. Basic Clin Neurosci. 2011;2(2):31-7.

29. Rabiei K, Ghobadifar A, Ebrahimzadeh MA, Saeedi M, Mobini M. Effects of ginger and elaeagnus angustifolia extracts in symptomatic knee osteoarthritis. Zahedan J Res Med Sci. 2015;17(11) doi: 10.17795/zjrms-2200.

30. Ge Y, Zhang F, Qin Q, Shang Y, Wan D. In Vivo Evaluation of the Antiasthmatic, Antitussive, and Expectorant Activities and Chemical Components of Three Elaeagnus Leaves. Evid Based Complement Alternat Med. 2015;2015:428208. doi: 10.1155/2015/428208. [PubMed: 26576193].

31. Tamtaji O, Taghizadeh M, Takhtfiroozeh S, Talaei S. The effect of elaeagnus angustifolia water extract on scopolamine-induced memory impairment in rats [In Persian]. J Zanjan Univ Med Sci. 2014;22(95):101. 